\title{
Hydrolytic performances of different organic compounds in different lignocellulosic biomass during anaerobic digestion
}

\author{
Haifeng Yang ${ }^{1 \dagger}$, Rui Deng ${ }^{2}$, Junwei Jin', Yuling $\mathrm{Wu}^{1}$, Xin Jiang ${ }^{1}$, Jinhua Shi ${ }^{1}$ \\ ${ }^{1}$ Ecological Environment Institute, Chongqing Municipal Research Institute of Design, Chongqing, P.R. China \\ ${ }^{2}$ Chongqing Jiaotong University, Chongqing, 400074, P.R. China
}

\begin{abstract}
Hydrolytic performances of different organic compounds in lignocellulosic biomass (LB) during anaerobic digestion (AD) are worth investigating due to the complex and refractory structure of lignocellulose. This study aimed to clarify the hydrolytic performances of different lignocellulosic components (hemicellulose, cellulose and lignin) and other typical organics (saccharides, protein and lipid) in AD process. Furthermore, an in-depth study of different lignocellulosic components mono-/co-digestive performances, as well as their effects on digestive systems were also designed to explain the mechanism. Kinetic models were specially applied to evaluate the hydrolytic process and make comparison among different lignocellulosic components. Results showed that hemicellulose obtained high degradation ratio (77.2-85.0\%) during anaerobic digestion, while cellulose was difficult to hydrolyze without sufficient acidity. And organics (saccharides, protein and lipid) were much easier to be hydrolyzed than lignocellulose. Results also depicted that lignocellulose addition could efficiently enhance the volatile solid (VS) removals of digestive systems, while lignin existing in systems reduced the VS removal. The limited hydrolysis of lignocellulose hindered the degradation of total VS in digester. It is quite important to obtain high bioenergy conversion, pretreatments, which can destroy the lignin wrapping in LBs digestion. This study could provide a reference for the $\mathrm{AD}$ of LBs.
\end{abstract}

Keywords: Anaerobic digestion (AD), Hydrolytic ratios and rates, Kinetic models, Lignocellulosic biomass (LB), Lignocellulosic components, Organics degradation

\section{Introduction}

In recent years, increasing attention has been paid on bioenergy recovery from biomass waste $[1,2]$. As a kind of dominating biomass waste, lignocellulosic biomass (LB), commonly includes crop straw, grass and leaves, waste paper pulp, municipal sludge and so on, it was widely applied in anaerobic digestion (AD) process [3]. During LBs' AD process, macromolecular organic compounds in LBs (lignocellulose, saccharides, protein and lipid) are firstly hydrolyzed to micromolecular organics (such as monosaccharide, amino acid, peptide, glycerin and so on) [4]. Then, acidogenesis and acetogenesis convert these micromolecular organics into acetic acid, $\mathrm{H}_{2}$ and $\mathrm{CO}_{2}$ [1]. Eventually, under the action of methanogens, these materials are further converted into biogas, dominated by methane [5]. In this cycle, hydrolysis is the rate-limiting step, and its duration depends on the properties of the substrates [6]. Among these substrates, lignocellulose is the most abundant organic matter in the world, and it is composed of hemicellulose, cellulose and lignin. These three kinds of substances commonly intertwine with each other and form a combined state. Due to the encapsulation of refractory lignin and the bonding of chemical bonds, constitutionally stable lignocellulose is commonly difficult to be hydrolyzed and utilized by microbes [7]. Previous study [8] found that the hydrolysis of LBs was much slower than other organic solid waste, which might be attributed to the refractory property of lignocellulose in LBs. Besides, lignocellulose structure is another important factor which can affect the digestive performances of LBs [9].

Lignocellulose comprised the main part of organic compounds in LBs, whose proportion were about $66-78 \%$ in crop straws [10], $75-94 \%$ in different grass [11], 64-75\% in different leaves [12] and $14-44 \%$ in excess sludge (ES) [12, 13]. The lignocellulosic contents in these LBs are different, and their composition and structure also vary a lot. For example, the structure of lignocellulose in ES is in a free state and theoretically, it should be more easily
This is an Open Access article distributed under the terms of the Creative Commons Attribution Non-Commercial License (http://creativecommons.org/licenses/by-nc/3.0/) which permits unrestricted non-commercial use, distribution, and reproduction in any medium, provided the original work is properly cited.

Copyright (C) 2022 Korean Society of Environmental Engineers
Received January 05, 2021 Accepted May 25, 2021

${ }^{\dagger}$ Corresponding author

E-mail: 1714353485@qq.com

Tel: +86 13678426821 Fax: +86 13678426821

ORCID: 0000-0001-7207-3506 
degraded by microbes during the $\mathrm{AD}$ process. However, previous study [1] showed that the total volatile solid (TS) degradation ratios are not high (around 30-50\%) after ES digestion, which deserved to be further clarified. Compared to other organics (saccharides, protein and lipid) in LBs, lignocellulose is more difficult to hydrolyze in $\mathrm{AD}$. Due to the different structure and composition of different lignocellulosic components, their hydrolytic rates and ratios vary a lot during the $\mathrm{AD}$ cycle [14]. Therefore, it is important to figure out the rate of hydrolysis and the rate of different lignocellulosic components. Even though previous studies [15] have quantitatively evaluated the degradation ratios of different lignocellulosic components in pretreatment period (such as acid, alkali, thermal and ultrasonic pretreatment) of LBs, the research related their degradation in LBs during the whole $\mathrm{AD}$ process is still limited, especially in digestion of complex substrates, such as sludge, kitchen waste and so on, not to mention the kinetic study of their degradation [16] studied the degradation of different organics (total solids (TS), VS, lipids and protein) during the different kinds of food waste digestion process by using several kinetic models, and evaluated the relationship between organics reduction and methane production. Therefore, it is essential to understand LBs' degradation by using kinetic models, especially different lignocellulose components.

Based on the analysis above, this study attempted to investigate the hydrolytic performances of different organic compounds (hemicellulose, cellulose, lignin, saccharides, protein and lipid) in several LBs (excess sludge (ES) and different crop straws) during the $\mathrm{AD}$ process. Kinetic models were applied to evaluate the hydrolytic performances of digestive systems and different lignocellulosic components. In addition, the mono-/co-digestibility of different lignocellulosic components in sludge was further studied to clarify its hydrolysis performance and its impact on the digestive system. The innovation of present study lies in the separation of lignocellulosic monomers, verification in real LBs, and analysis by applying kinetic models. This study tried to provide some ideas and directions for the future researches of LBs' digestion.

\section{Materials and Methods}

\subsection{Experimental Materials}

In this study, excess sludge (ES), corn cob (CC), corn straw (CS), wheat straw (WS) and rice straw (RS) were chosen to represent different kind of LBs. ES was taken from the secondary sedimentation tank of Tangjiatuo sewage treatment plant, Chongqing. This plant adopts anaerobic-anoxic-oxic $(\mathrm{A} / \mathrm{A} / \mathrm{O})$ biochemical treatment process with a treatment capacity of 400 thousand tons of sewage per day. After one-day gravity precipitation, ES was immediately characterized by its VS and lignocellulosic content, and the remains were stored at $4^{\circ} \mathrm{C}$ before using. CC, CS, WS and RS were collected from a farm. They were air-dried and then ground into small particles by a mill. The particles were sieved through 20 and 100 mesh sieves respectively to remove the larger and smaller particles. Xylan (HWG25024, HWRK), $\alpha$-cellulose (C104841, Aladdin) and lignin (L195713, Aladdin) were respectively applied as representatives of hemicellulose, cellulose and lignin [17]. A kind of synthetic sludge (SS) was derived from the sedimentation tank of an $\mathrm{A} / \mathrm{O}$ reactor in our laboratory. This reactor was fed with ammonium bicarbonate and glucose solution (COD $=1,600$ $\mathrm{mg} / \mathrm{L}$ ) every day. Due to no exogenous lignocellulosic addition, SS contained no lignocellulose component. Inocula were the digested sludge taken from our laboratory (SRT $=25 \mathrm{~d}$, TS $=5.5 \%$ ). The digested sludge was sampled and stored under anaerobic condition at $37 \pm 1^{\circ} \mathrm{C}$ for one week to remove organics as much as possible. All feedstock was stored in the $4^{\circ} \mathrm{C}$ condition before used. The characteristics of different feedstock' components are listed in Table 1.

\subsection{Experimental Design}

This study was divided into two tests. Test I aimed to explore the hydrolytic performances of different kinds of LBs (ES, CC, CS, WS and RS) in batch digester. The total lignocellulose amounts in different digester were controlled in accordance with that in ES. Experimental design of Test I is shown in Table 2. Based on the results of Test I, Test II was designed to explore the hydrolytic performances of different kind of lignocellulosic components in batch digester. The focus of this test was to examine the effects of different lignocellulose components on the hydrolysis of the system. Experimental design of Test II is also shown in Table 2. It could be noticed that the added amounts of xylan, $\alpha$-cellulose and lignin were in accordance with the measured contents in ES.

Batch digesters were several serum bottles with effective volume

Table 1. Characteristics of Different Feedstock's Components

\begin{tabular}{|c|c|c|c|c|c|c|c|c|c|c|c|}
\hline Parameters & Units & ES & SS & CC & CS & WS & RS & Xylan & $\alpha$-cellulose & Lignin & Inocula \\
\hline TS & $\%$ & 3.8 & 2.8 & 88.9 & 88.6 & 89.0 & 91.5 & 97.9 & 97.1 & 97.1 & 5.4 \\
\hline VS & $\%$ & 2.1 & 1.5 & 87.3 & 82.7 & 79.5 & 81.1 & 97.8 & 97.0 & 96.8 & 2.2 \\
\hline $\mathrm{pH}$ & - & 6.96 & 8.04 & - & - & - & - & - & - & - & 7.21 \\
\hline Crude protein & \%TS & 8.3 & 31.6 & 3.3 & 4.5 & 3.9 & 4.6 & - & - & - & 18.3 \\
\hline Crude fat & \%TS & 6.9 & 18.3 & 2.4 & 2.1 & 2.8 & 2.5 & - & - & - & 21.4 \\
\hline Carbohydrate & \%TS & 15.3 & 5.4 & 91.6 & 82.7 & 79.2 & 76.5 & - & - & - & 4.3 \\
\hline Saccharides & \%TS & 0.3 & 5.4 & 6.1 & 12.9 & 9.0 & 11.3 & - & - & - & 2.6 \\
\hline Hemicellulose & \%TS & 17.5 & - & 41.7 & 28.1 & 23.0 & 28.4 & 99.3 & - & - & 0.4 \\
\hline Cellulose & \%TS & 7.3 & - & 36.9 & 35.5 & 38.7 & 32.0 & - & 99.6 & - & 1.2 \\
\hline Lignin & \%TS & 15.0 & - & 7.8 & 10.2 & 11.9 & 9.8 & - & - & 99.4 & 0.1 \\
\hline Lignocellulose & \%TS & 39.8 & - & 86.4 & 73.8 & 73.6 & 70.2 & 99.3 & 99.6 & 99.4 & 1.7 \\
\hline
\end{tabular}


Table 2. Experimental Design of Test I and Test II

\begin{tabular}{|c|c|c|c|c|c|c|c|c|c|c|c|c|c|c|c|}
\hline \multirow[b]{2}{*}{ Test } & \multirow[b]{2}{*}{ Digester } & \multirow[b]{2}{*}{$\begin{array}{c}\text { SS } \\
(\mathrm{mL})\end{array}$} & \multirow[b]{2}{*}{$\begin{array}{c}\text { ES } \\
(\mathrm{mL})\end{array}$} & \multirow[b]{2}{*}{$\begin{array}{l}\text { CC } \\
\text { (g) }\end{array}$} & \multirow[b]{2}{*}{$\begin{array}{l}\text { CS } \\
\text { (g) }\end{array}$} & \multirow[b]{2}{*}{$\begin{array}{l}\text { WS } \\
\text { (g) }\end{array}$} & \multirow[b]{2}{*}{$\begin{array}{l}\text { RS } \\
\text { (g) }\end{array}$} & \multicolumn{3}{|c|}{ Added representatives } & \multirow[b]{2}{*}{$\begin{array}{l}\text { VS } \\
\text { (g) }\end{array}$} & \multirow{2}{*}{$\begin{array}{l}\text { Hemicellulose } \\
\text { content } \\
\text { (g) }\end{array}$} & \multirow{2}{*}{$\begin{array}{c}\text { Cellulose } \\
\text { content } \\
\text { (g) }\end{array}$} & \multirow{2}{*}{$\begin{array}{c}\text { Lignin } \\
\text { content } \\
\text { (g) }\end{array}$} & \multirow{2}{*}{$\begin{array}{l}\text { Lignocellulose } \\
\text { content } \\
\text { (g) }\end{array}$} \\
\hline & & & & & & & & $\begin{array}{c}\text { Xylan } \\
\text { (g) }\end{array}$ & $\begin{array}{l}\alpha \text {-cellulose } \\
\text { (g) }\end{array}$ & $\begin{array}{l}\text { Lignin } \\
\text { (g) }\end{array}$ & & & & & \\
\hline \multirow{6}{*}{ I } & $\mathrm{S} 1^{*}$ & 330 & - & - & - & - & - & - & - & - & 5.0 & - & - & - & 0 \\
\hline & $\mathrm{S} 2$ & - & 350 & - & - & - & - & - & - & - & 7.5 & 2.31 & 0.97 & 1.98 & 5.26 \\
\hline & S3 & 44 & - & 6.8 & - & - & - & - & - & - & 7.5 & 2.54 & 2.25 & 0.47 & 5.26 \\
\hline & S4 & 56 & - & - & 8.0 & - & - & - & - & - & 7.5 & 2.00 & 2.53 & 0.73 & 5.26 \\
\hline & S5 & 74 & - & - & - & 8.0 & - & - & - & - & 7.5 & 1.65 & 2.76 & 0.85 & 5.26 \\
\hline & S6 & 56 & - & - & - & - & 8.5 & - & - & - & 7.5 & 2.13 & 2.40 & 0.73 & 5.26 \\
\hline \multirow{8}{*}{ II } & $\mathrm{L}^{*}{ }^{*}$ & 330 & - & - & - & - & - & - & - & - & 5.0 & - & - & - & 0 \\
\hline & L2 & 340 & - & - & - & - & - & 2.37 & - & - & 7.5 & 2.31 & - & - & 2.31 \\
\hline & L3 & 330 & - & - & - & - & - & - & 1.00 & - & 6.0 & - & 0.97 & - & 0.97 \\
\hline & L4 & 330 & - & - & - & - & - & - & - & 2.05 & 7.0 & - & - & 1.98 & 1.98 \\
\hline & L5 & 278 & - & - & - & - & - & 2.37 & 1.00 & - & 7.5 & 2.31 & 0.97 & - & 2.28 \\
\hline & L6 & 211 & - & - & - & - & - & 2.37 & - & 2.05 & 7.5 & 2.31 & - & 1.98 & 4.29 \\
\hline & L7 & 300 & - & - & - & - & - & - & 1.00 & 2.05 & 7.5 & - & 0.97 & 1.98 & 2.95 \\
\hline & L8 & 148 & - & - & - & - & - & 2.37 & 1.00 & 2.05 & 7.5 & 2.31 & 0.97 & 1.98 & 5.26 \\
\hline
\end{tabular}

* Digester S1 and group L1 were in the same substrates and experimental conditions.

of $450 \mathrm{~mL}$. Before experiment, different kind of feedstock was added into digesters following the designed formulas. After addition, the rubber stopper was used to seal the bottle, and nitrogen was bubbled through eyelet in rubber stopper for 5 min to obtain the anaerobic condition. After that, the bottles were heated at $37 \pm 1^{\circ} \mathrm{C}$ and shaken at $140 \mathrm{rpm}$ in a water-bath pot. The experimental period was set at $38 \mathrm{~d}$. All experiments were performed in three replicates.

\subsection{Analytical Methods}

Biogas for different digesters were collected by $500 \mathrm{~mL}$ gas bags from the eyelet in rubber stopper. A $250 \mathrm{~mL}$ syringe was used to measure biogas production. Digestates of different digesters were sampled at specific time points. Soluble chemical oxygen demand (SCOD), total solid (TS) and volatile solid (VS) were measured according to standard methods [18]. Biogas composition was measured using a gas chromatograph (Jiedao GC1690, Hangzhou) with a thermal conductivity detector (TCD). Specific measuring process was shown in previous study [19]. $\mathrm{pH}$ values of different digesters were measured by a $\mathrm{pH}$ meter (PHS-3S, Leici). Protein in the feedstock was determined through analyzing the concentration of total Kjeldahl nitrogen by a Kjeldahl apparatus (K1305A, Shanghai). Soxhlet extraction method was applied in measuring lipid. Carbohydrates were calculated by subtracting the amount of protein and lipid from total VS. Lignocellulosic components were analyzed using the method developed by Van Soest et al. [20]. Saccharides were calculated by subtracting the total amount of lignocellulose from carbohydrates.

\subsection{Kinetic Study}

Fitzhugh model and modified Gompertz model were applied to explore the hydrolytic and methanogenic performances of different digesters. Hydrolytic constant $k$ value $\left(\mathrm{d}^{-1}\right)$, which is fitted by Fitzhugh model, can be applied to represent the hydrolytic rate of digestive system [16]. In general, a higher $k$ value indicates a higher hydrolytic rate of digester system. This model is shown in Eq. (1):

$$
B=B_{0} \cdot[1-\exp (-k \cdot t)]
$$

Where $B$ represents experimental specific biogas yields ( $\mathrm{mL}$ biogas/g VS) for digestion time $t$ (d), $B_{0}$ represents simulative specific biogas yields ( $\mathrm{mL}$ biogas/g VS), and $k\left(\mathrm{~d}^{-1}\right)$ represents hydrolytic constant.

Modified Gompertz model was used to determine the maximum methane production rate and lag phase for $\mathrm{AD}$ process by fitting the experimental specific methane yields [18]. This model is shown in Eq. (2):

$$
M_{t}=M_{0} \cdot \exp \left\{-\exp \left[\frac{R_{\max } \cdot \mathrm{e}}{M_{0}} \cdot(\lambda-t)+1\right]\right\}
$$

Where $M_{t}$ represents experimental specific methane yield (mL/g VS) for digestion time $t$ (d); $M_{0}$ is the simulative specific methane yield (mL/g VS); $R_{\max }$ is the maximum methane production rate $(\mathrm{mL} / \mathrm{g} \mathrm{VS} / \mathrm{d}) ; \lambda$ is the lag phase $(\mathrm{d})$.

Furthermore, another kinetic model-First-order model was applied to analyze the hydrolytic performances of different lignocellulosic components by fitting their degradation data throughout the $\mathrm{AD}$ process [16]. This model is shown in Eq. (3)-(4):

$$
\begin{gathered}
\frac{\mathrm{d} C}{\mathrm{~d} t}=-k \cdot C \\
\mathrm{C}_{\mathrm{t}}=\mathrm{C}_{0} \cdot \mathrm{e}^{-\mathrm{kt}}
\end{gathered}
$$

Where $C$ represents degradation ratio of different kind of lignocellulosic component (\%) for digestion time $t$ (d), $C_{0}$ represents experimental degradation ratio (\%), and $k\left(\mathrm{~d}^{-1}\right)$ represents hydrolytic 
constant of different kinds of lignocellulosic components. A higher $k$ value indicated a higher hydrolytic rate of lignocellulosic component.

The experimental data were analyzed using Office Excel 2016, and kinetics were fitted and analyzed by software Origin 8.0 [21].

\section{Results and Discussion}

\subsection{Biogas Production}

Fig. 1 depicts the experimental specific biogas and methane yield of different digesters throughout the $\mathrm{AD}$ process. From this figure, it could be observed that different crop straws (CC, CS, WS and RS)-added digesters presented obviously higher cumulative biogas and methane yields than sludge (SS and ES). WS-added digester (S5) obtained the highest biogas and methane yields (490.4 and $287.0 \mathrm{~mL} / \mathrm{g}$ VS, respectively) among all digesters due to WS's organic composition and specific lignocellulosic texture, which has been discussed adequately in previous study [22]. In this study, hydrolysis of substrates was much more focused than biogas yield, thus Fitzhugh model and modified Gompertz model were applied, and the obtained kinetic fitting results were shown in Table 3.
Fitting results of Fitzhugh model were shown in the left column of Table 3 (Test I). Hydrolytic constant (k) values fitted by this Fitzhugh model reflect the hydrolytic rates of the whole digestive system. The $\mathrm{k}$ values for S1-S6 were 0.060, 0.044, 0.060, 0.031, 0.049 and $0.037 \mathrm{~d}^{-1}$, respectively. SS and CC-added digesters presented higher hydrolytic rates than other digesters during the $\mathrm{AD}$ process. Hydrolytic rates of other LBs-added digesters were lower than digester S1, which was due to the huge amount of lignocellulose containing in substrates. Although there was the same amount of lignocellulose in digester S3, the hydrolytic rate of this digester was relative higher than other LBs-added digesters, which could be attributed to the high hemicellulose content (shown in Table 1 and 2) and the looser wrapping of lignocellulose in CC [22]. The result can also verify that CC is an ideal lignocellulosic substrate applying in digestion for its good hydrolytic performance.

The right column of Table 3 (Test I) shows the fitting results of modified Gomportz model. From the fitting results, $R_{\max }$ and $\lambda$ can reflect the response rate of microbes to substrates. A smaller $\lambda$ value indicates a better adaptability of microbes [23], and a higher $R_{\max }$ indicates the higher activity of methanogens in the digestive system. From this table, it could be noticed that $\lambda$ value in digester S2 (ES) was obviously higher than others (as high
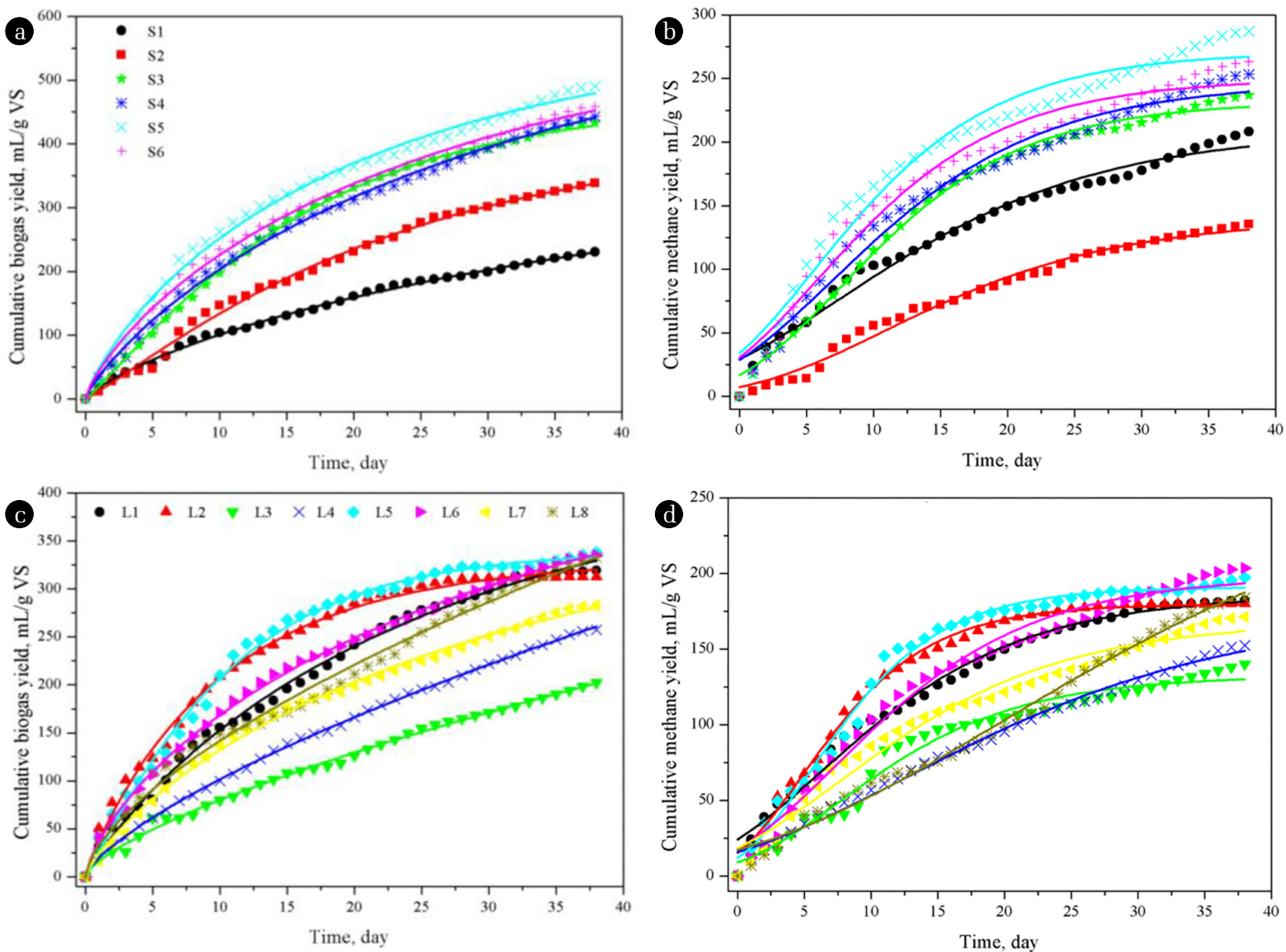

Fig. 1. (a) Kinetic fitting of experimental specific biogas yields (b) and experimental specific methane yields of Test I. (c) Kinetic fitting of experimental specific biogas yields (d) and experimental specific methane yields of Test II. 
Table 3. Kinetic Fitting Results of Hydrolysis and Methanogenesis in Different Digesters

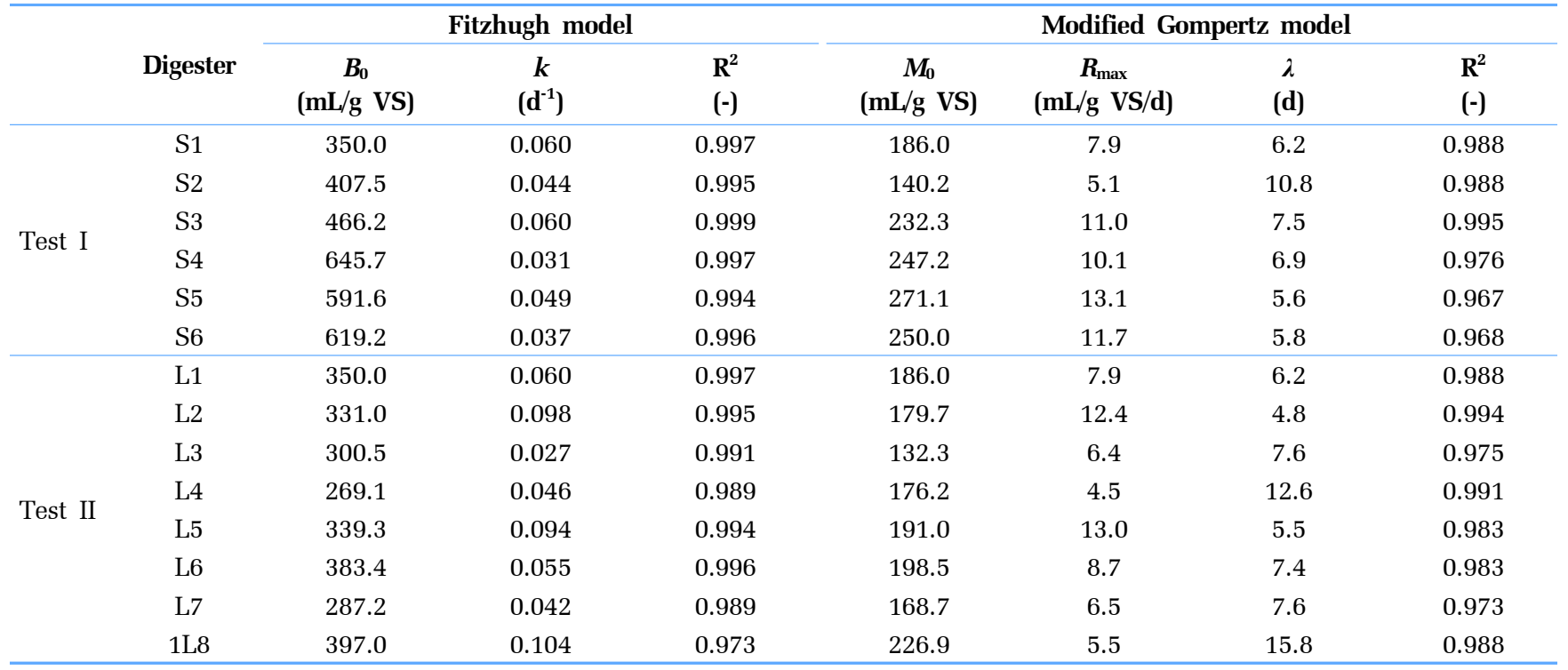

as $10.8 \mathrm{~d}$ ), which was due to the long generations of methanogens in single ES system [24]. However, the values of $\lambda$ were greatly shortened in crop straws (CC, CS, WS and RS)-added digesters (5.6-7.5 d), indicating that these types of crop straws (CC, CS, WS and RS) addition could enhance the gasogenic efficiency and microbial function. The unique structures of crop straws could provide suitable adhesion condition for microbes, which is conducive to enrich microbial abundance and to alleviate the inhibitory effects of the intermediates (such as volatile fatty acids and ammonia) on methanogens [25].

In the Test I, hydrolytic performances of different LBs were investigated during the $\mathrm{AD}$ process, and the results showed that different LBs presented different hydrolytic performances due to their different lignocellulosic compositions and structure. In order to further explore the mono-/co-digestive properties of different lignocellulosic monomers and their effects on system hydrolysis, Test II was conducted.

Fig. 1 shows the experimental specific biogas and methane yield of different lignocellulosic monomers-added digesters. From this figure, significant differences in biogas/methane production could be observed among different digesters, indicating that different lignocellulosic monomers presented different effects on system hydrolysis and methane yield. Specific gasogenic performances and kinetic study results are shown in Table 3(Test II).

Fitting results of Fitzhugh model are shown in the left column of Table 3(Test II). From this column, it can be observed that the hydrolytic constants $(k)$ in L1-L8 were $0.060,0.098,0.027$, $0.046,0.094,0.055,0.042$ and $0.104 \mathrm{~d}^{-1}$, respectively. The $k$ values of hemicellulose-added digesters were much higher than others, which could be used to explain why the hydrolytic efficiency of CC (whose hemicellulose content was 41.7\%) was the highest among all kinds of LBs in Test I. In addition, it could be observed that the hydrolytic rates of free-state lignocellulosic components were much higher than these in different LBs in Test I, indicating that the digestive efficiency could be enhanced by breaking down the lignocellulose fiber before digestion. The lowest $k$ value was obtained in digester L3 (with solo cellulose addition), verifying that cellulose can hardly be hydrolyzed in limit-acidity condition. Compared to digester L3, digester L5 (hemicellulose and cellulose co-addition) presented a higher hydrolytic rate, which can be ascribed to the acceleration of cellulose hydrolysis caused by hemicellulose addition [26]. However, the hydrolytic constant of digester L7 (cellulose and lignin co-addition) was about $0.042 \mathrm{~d}^{-1}$, which is quite close to that in digester LA (solo lignin addition), indicating that the presence of lignin can hardly affect the hydrolysis of cellulose.

Fitting results of modified Gompertz model (in right column) showed that hemicellulose-added digesters (L2 and L5) presented higher rates of methane yield. However, $R_{\max }$ of digester L6 and L8 were not as high as expected, which was due to the acid inhibition caused by the fast hydrolysis and acidification of substrates. Furthermore, long lag phases $(\lambda)$ were observed in lignin-added digesters (L4, L6, L7 and L8), indicating that delignification is beneficial to obtain better $\mathrm{AD}$ operations.

\subsection{Lignocellulosic Components Degradation}

During the $\mathrm{AD}$ process, biological energy was recovered, and organic compounds (lignocellulose, sugars, proteins and lipids) in the raw materials were degraded at the same time. Fig. 3 shows the degradation of lignocellulose in different kind of LBs (Test I) during the $\mathrm{AD}$ process. First-order kinetic model was applied to fit these data to obtain hydrolytic constants of these lignocellulosic components, and the results were shown in Table 4. The hemicellulose obtained high degradation ratio (77.2-85.0\%) in all digesters. Hemicellulose in ES presented obviously higher degradation ratio (85.0\%) and rates $\left(0.094 \mathrm{~d}^{-1}\right)$ than other digesters, which might be attributed to the free state of hemicellulose in ES [24], and its amorphous nature [27]. Due to the wrap of lignin structure, hemicellulose in other LBs were not liable to contact with microbes and related enzymes before the lignin structure was broken [28]. Cellulose 
degradation ratios in these digesters (29.7-47.6\%) were much lower than hemicellulose. Particularly, due to the alkaligenous character of ES hydrolysis [29], insufficient acidity caused the inadequate hydrolysis of cellulose, resulting in the lowest cellulose degradation (29.7\%) in this digester. Compared to ES, hydrolysis of other LBs brought obvious drops of $\mathrm{pH}$ values (6.4-6.7), which was in favor of the cellulose hydrolysis. It is also confirmed that lignin can hardly be hydrolyzed and degraded, whose degradation ratios varied from $4.9 \%$ to $8.7 \%$.

From Table 4, it can be concluded that the hydrolytic rates of these lignocellulosic components depend heavily on their properties [30]. Hemicellulose in these LBs presented higher hydrolytic rates (0.069-0.094 $\left.\mathrm{d}^{-1}\right)$ than both cellulose (0.032-0.050 $\left.\mathrm{d}^{-1}\right)$ and lignin (0.003-0.005 $\left.\mathrm{d}^{-1}\right)$, which was consistent with their higher degradation rate. By horizontally comparing the hydrolytic rates of these LBs, it can be drawn that ES presented the highest hemicellulose hydrolytic rate $\left(0.094 \mathrm{dy}^{1}\right)$ and the lowest cellulose hydrolytic rate $\left(0.032 \mathrm{~d}^{-1}\right)$ than other LBs, which was in highly consistent with their degradation ratios at the end of the digestion.

Fig. 2 (Test II) shows the degradation of different lignocellulosic monomers and their First-order model fitting curves. Kinetic fitting results of different lignocellulosic monomers' degradation were shown in Table 4. Hemicellulose presented high degradation ratios (85.8-88.7\%), which were obviously higher than that in different LBs (77.2-85.0\%) in Test I. The relatively lower hemicellulose degradation in LBs were due to the wrapping of lignin in lignocellulosic fiber [31]. In test II the added hemicellulose was in free state, and so higher degradation ratios were obtained. For cellulose, different digesters showed different degradation ratios. It should be noticed that, compared to digesters L3 and L7 (40.4\% and 50.5\%, respectively), more cellulose was degraded in hemicellulose-added digesters (63.0\% for L5 and $68.2 \%$ for L8). There might be two reasons for this. On the one hand, the hydrolysis of hemicellulose promoted the acidity in slurry and thus enhanced the hydrolysis of cellulose. On the other hand, due to chemical bond connection, there was a synergistic effect between hemicellulose and cellulose,
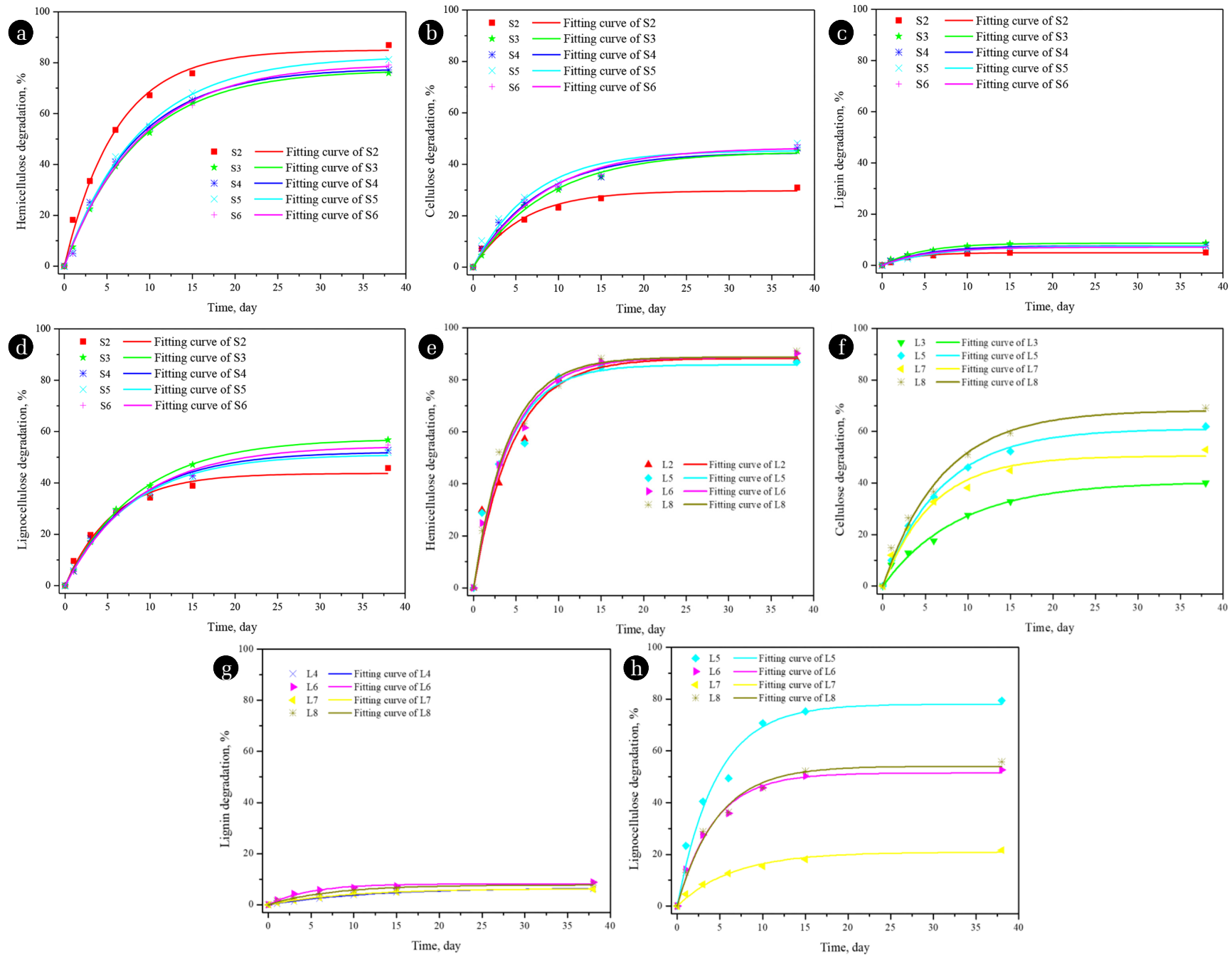

Fig. 2. First-order model fitting of different lignocellulosic components degradation during the AD process ((a)-(d) Test I, (e)-(h) Test II). (a), (e) Hemicellulose; (b), (f) Cellulose; (c), (g) Lignin; (d), (h) Total lignocellulose) 
Table 4. Removal Ratios of Different Lignocellulosic Components and Their Hydrolytic Rates

\begin{tabular}{|c|c|c|c|c|c|c|c|c|c|c|c|c|c|}
\hline Substrates & Parameters & S2 & S3 & S4 & S5 & S6 & L2 & L3 & L4 & L5 & L6 & L7 & L8 \\
\hline \multirow{3}{*}{ Hemicellulose } & Removal (\%) & 85 & 77.2 & 77.9 & 82.5 & 79.6 & 88.3 & - & - & 85.8 & 88.6 & - & 88.7 \\
\hline & $k\left(\mathrm{~d}^{-1}\right)$ & 0.094 & 0.07 & 0.072 & 0.077 & 0.069 & 0.133 & - & - & 0.125 & 0.133 & - & 0.137 \\
\hline & $\mathrm{R}^{2}$ & 0.992 & 0.999 & 0.996 & 0.997 & 0.996 & 0.96 & - & - & 0.956 & 0.986 & - & 0.985 \\
\hline \multirow{3}{*}{ Cellulose } & Removal (\%) & 29.7 & 45.4 & 44.6 & 46.7 & 47.6 & - & 40.4 & - & 63 & - & 50.5 & 68.2 \\
\hline & $k\left(\mathrm{~d}^{-1}\right)$ & 0.032 & 0.035 & 0.044 & 0.05 & 0.047 & - & 0.025 & - & 0.049 & - & 0.037 & 0.058 \\
\hline & $\mathrm{R}^{2}$ & 0.98 & 0.961 & 0.978 & 0.985 & 0.995 & - & 0.978 & - & 0.995 & - & 0.977 & 0.984 \\
\hline \multirow{3}{*}{ Lignin } & Removal (\%) & 4.9 & 8.7 & 7.7 & 7.6 & 7.1 & - & - & 6.6 & - & 8.2 & 6.3 & 7.8 \\
\hline & $k\left(\mathrm{~d}^{-1}\right)$ & 0.003 & 0.005 & 0.005 & 0.005 & 0.004 & - & - & 0.003 & - & 0.005 & 0.003 & 0.004 \\
\hline & $\mathrm{R}^{2}$ & 0.992 & 0.989 & 0.993 & 0.993 & 0.987 & - & - & 0.998 & - & 0.979 & 0.997 & 0.988 \\
\hline \multirow{3}{*}{ Lignocellulose } & Removal (\%) & 43.7 & 57.3 & 52.2 & 51.1 & 54.5 & - & - & - & 78.1 & 51.5 & 20.9 & 54.1 \\
\hline & $k\left(\mathrm{~d}^{-1}\right)$ & 0.031 & 0.043 & 0.037 & 0.035 & 0.036 & - & - & - & 0.092 & 0.044 & 0.033 & 0.046 \\
\hline & $\mathrm{R}^{2}$ & 0.985 & 0.999 & 0.995 & 0.993 & 0.995 & - & - & - & 0.969 & 0.987 & 0.983 & 0.985 \\
\hline
\end{tabular}

which has been shown in previous study [32, 33]. However, digester L3 (with solo cellulose addition) obtained the lowest cellulose degradation ratio $(40.4 \%)$ at the end of the digestion. The ratio was even lower than that in different LBs (44.6-47.6\%) in test I, which was mainly due to the acidity produced in this digester. Generally speaking, if the acidity in hydrolytic stage could be guaranteed, free-state cellulose was more liable to be degraded than that in lignocellulosic fibers [34, 35]. So, it is meaningful to enhance hydrolysis of lignocellulose in LBs by breaking its fiber structure. The results indicated that the improving the hydrolytic efficiency of cellulose is key to promoting the digestive performances of LBs as well [36].

Table 4 shows the kinetic fitting results of different lignocellulosic monomers' degradation. By comparing the fitting results of hemicellulose, cellulose and lignin in digester L2, L3 and L4, it could be observed that the hemicellulose hydrolytic rates $\left(0.133 \mathrm{~d}^{-1}\right)$ were much higher than cellulose $\left(0.025 \mathrm{~d}^{-1}\right)$ and lignin $(0.003$ $\mathrm{d}^{-1}$ ). In the co-addition system (L5-L8), the hydrolysis rate of the corresponding lignocellulosic monomers was increased, confirming the synergy between these lignocellulosic components. In addition, hydrolytic rates of total lignocellulose were also investigated. Results found that the hydrolytic rate of cellulose and lignin co-addition (L7, $0.033 \mathrm{~d}^{-1}$ ) was only a few higher than mono-digesters $\left(0.025 \mathrm{~d}^{-1}\right.$ for cellulose and $0.003 \mathrm{~d}^{-1}$ for lignin), indicating that hemicellulose could contribute more to synergistic effects.

\subsection{Total VS Degradation}

After 38-day digestion, VS removals of different digesters were also recorded. VS removals for digester S1-S6 were 38.5\%, 42.3\%, $68.9 \%, 66.3 \%$, 65.3\% and 62.4\%, respectively. These removed VS can be divided into two parts: lignocellulose (hemicellulose, cellulose and lignin) and other organics (saccharides, protein and lipid). It can be seen from Fig. 3 (Test I), that lignocellulose degradation ratios for S2-S6 were $45.8 \%, 56.8 \%, 52.7 \%, 52.0 \%$ and $54.8 \%$, while other organics degradation ratios for S2-S6 were $54.0 \%, 97.0 \%$, $98.3 \%, 96.7 \%$ and $80.4 \%$, respectively. The highest degradation ratio of saccharide was due to the fact that it is the most susceptible to be hydrolyzed and utilized by microbes. In addition, it can be noticed that the protein and lipid degradation ratios were also higher than previous studies, due that the lignocellulosic fiber in LBs provided attachment points for them, which was conducive to their removals $[37,38]$. In addition, owing to the low contents of protein and lipid contents in LBs, they were more liable to be consumed. Comparing the VS degradation ratios, conclusions could be drawn that other organics (saccharides, protein and lipid) were much easier to be hydrolyzed than lignocellulose (particularly cellulose and lignin).Therefore, hydrolysis of cellulose in LBs rather than other organics, is the critical step of LBs digestion. Researchers should pay more attention on the hydrolysis of lignocellulose (especially the cellulose component) because of its limited degradation ratio in $\mathrm{AD}$ process..

After 38-day digestion, VS degradation ratios for different lignocellulosic components-added digesters were also investigated. Fig. 3(a) (Test II) shows that hemicellulose addition could efficiently enhance the VS removals of digestive systems, while lignin existing in systems reduce the VS removal. Even if the digester with cellulose (L3) added alone has a VS degradation rate of only 43.5\%, co-addition of hemicellulose and cellulose (L5) could enhance the VS degradation ratio of $61.1 \%$. The result proved that there was a good synergistic effect between these two components. Fig. 3(b) (Test II) shows the degradation ratios of VS in other organics (saccharides, protein and lipid). It should be noticed that saccharides are much easier to be hydrolyzed than protein and lipid in these digesters, and lignin addition (digesters L4, L6, L7 and L8) could induce the degradation of protein and lipid, which might be attributed to the enhancement of hydrolysis by acidic groups attached on lignin surface [39]. By comparing the degradation ratios of protein and lipid in the Test I and II, it can be observed that their degradation ratios in the Test II (about 50\% and 30\%, respectively) were much lower than those in the Test I (about 90\% and 80\%, respectively). Lignocellulose used in the Test I was in combined state, which may cause this situation, and its frame could form a good adsorption towards protein and lipid, which is quite beneficial to its degradation 

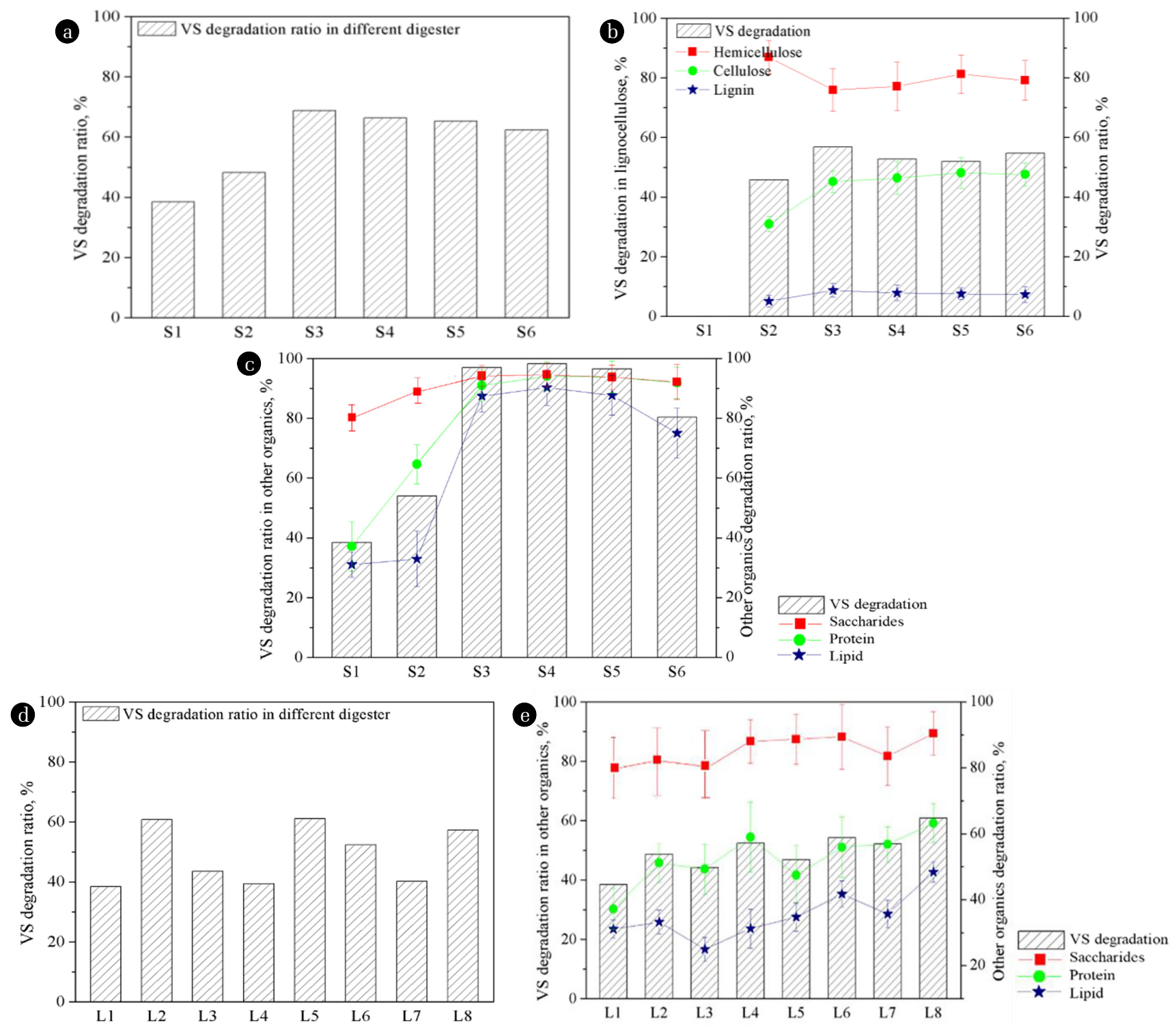

Fig. 3. Degradation of VS in different LBs after the AD process ((a)-(c) Test I, (d)-(e) Test II). (a), (d) VS in system; (b) VS in lignocellulose; (c), (e) VS in other organics.

and conversion to biogas. However, the free-state lignocellulose in the Test II can hardly adsorb these organics and pose positive effect on their further conversion.

\section{Conclusions}

This study investigated the hydrolytic performances and kinetic analysis of different kinds of LBs and lignocellulosic components in $\mathrm{AD}$. The results showed that the addition of crop straws (CC, CS, WS and RS) could improve the gas production efficiency and microbial function in the anaerobic digestion process, while the digester with CC added shows the best hydrolysis performance and the highest VS degradation rate (68.9\%) owing to its rich hemi- cellulose content.

However, free-state hemicellulose presented higher degradation ratios than that in combined state (in LBs). Results showed that hemicellulose obtained high degradation ratio (77.2-85.0\%) during anaerobic digestion, while cellulose was difficult to hydrolyze without sufficient acidity. Results also depicted that lignocellulose addition could efficiently enhance the VS removals of digestive systems, while lignin existing in systems reduced the VS removal. The limited hydrolysis of lignocellulose hindered the degradation of total VS in digester. Therefore, in order to obtain high bioenergy conversion, some measures (such as pretreatment and inoculum acclimation) should be applied to improve the hydrolysis performance of cellulose. This study could provide some ideas and directions for the future researches of LBs' digestion. 


\section{Acknowledgments}

The authors would like to acknowledge Shiyanjia Lab (www. shiyanjia.com) for providing the tests of carbohydrates, lipid and protein.

\section{Author Contributions}

H.Y. (M.D.) conducted all the experiments and wrote the manuscript independently. R.D. (Associate Professor), J.J. (M.D.) and Y.W. (B.D.) participated in the coordination of the study and reviewed the manuscript. X.J. (M.D.) and J.S. (M.D.) helped analyze the results and assisted in the experiments. All authors read and approved the final manuscript.

\section{References}

1. Li H, Si D, Liu C, Feng K, Liu C. Performance of direct anaerobic digestion of dewatered sludge in long-term operation. Bioresour. Technol. 2018;250:355-364.

2. Ma H, Guo Y, Qin Y, Li Y. Nutrient recovery technologies integrated with energy recovery by waste biomass anaerobic digestion. Bioresour. Technol. 2018;269:520-531.

3. Sawatdeenarunat C, Surendra K, Takara D, Oechsner H, Khanal S. Anaerobic digestion of lignocellulosic biomass: Challenges and opportunities. Bioresour. Technol. 2015;178:178-186.

4. Phuttaro C, Sawatdeenarunat C, Surendra K, Boonsawang P, Chaiprapata S, Khanal S. Anaerobic digestion of hydrothermally-pretreated lignocellulosic biomass: Influence of pretreatment temperatures, inhibitors and soluble organics on methane yield. Bioresour. Technol. 2019;284:128-138.

5. Chen S, Li N, Dong B, Zhao W, Dai L, Dai X. New insights into the enhanced performance of high solid anaerobic digestion with dewatered sludge by thermal hydrolysis: Organic matter degradation and methanogenic pathways. J. Hazard. Mater. 2018;342:1-9.

6. Hassan M, Umar M, Ding W, Mehryar E, Zhao C. Methane enhancement through co-digestion of chicken manure and oxidative cleaved wheat straw: Stability performance and kinetic modeling perspectives. Energy 2017;141:2314-2320.

7. Hu Y, Hao X, Wang J, Cao Y. Enhancing anaerobic digestion of lignocellulosic materials in excess sludge by bioaugmentation and pre-treatment. Waste Manage. 2015;49:55-63.

8. Tsapekos P, Kougias P, Kuthiala S, Angelidaki I. Co-digestion and model simulations of source separated municipal organic waste with cattle manure under batch and continuously stirred tank reactors. Energ. Convers. Manage. 2018;159:1-6.

9. Chen Y, Zhao Z, Zou H, et al. Digestive performance of sludge with different crop straws in mesophilic anaerobic digestion. Bioresour. Technol. 2019;289;122595.

10. Karthikeyan O, Visvanathan C. Bioenergy recovery from high-solid organic substrates by dry anaerobic bio-conversion processes: a review. Rev. Environ. Sci. Biotechnol. 2012;12: 257-284.
11. Monlau F, Barakat A, Trably E, Dumas C, Steyer J, Carrère $\mathrm{H}$. Lignocellulosic materials into biohydrogen and biomethane: impact of structural features and pretreatment. Crit. Rev. Environ. Sci. Technol. 2013;43:260-322.

12. Hao X, Cao X, Wang J, Hu Y. Feasibility analyses of stabilization and energy conversion of lignocelluloses contained in excess sludge. Acta Sci. Circumstantiate. 2013;33:1215-1223.

13. Buaisha M, Balku S, Özalp-Yaman Ş. Heavy Metal Removal Investigation in Conventional Activated Sludge Systems. Civil Eng. J. 2020;3;6:470-477.

14. Alonso V, Martín A, Borja R. Anaerobic digestion of wastewater produced in the manufacture of cellulosic pulp from wheat straw in immobilised cell bioreactors. Resour. Conserv. Recy. 1995;13:129-138.

15. Subhash P, Animesh D. Challenges and opportunities of lignocellulosic biomass for anaerobic digestion. Resour. Conserv. Recy. 2018;130:164-174.

16. Li Y, Jin Y, Li H, Borrion A, Yu Z, Li J. Kinetic studies on organic degradation and its impacts on improving methane production during anaerobic digestion of food waste. Appl. Energ. 2018;213:136-147.

17. Li W, Khalid H, Zhu Z, et al. Methane production through anaerobic digestion: Participation and digestion characteristics of cellulose, hemicellulose and lignin. Appl. Energ. 2018;226: 1219-1228.

18. American Public Health Association (APHA). Am Public Heal Assoc Stand Methods Exam Water Wastewater. 1995.

19. Zou H, Chen Y, Shi J, et al. Mesophilic anaerobic co-digestion of residual sludge with different lignocellulosic wastes in the batch digester. Bioresour. Technol. 2018;268:371-381.

20. Van S, Robertson J, Lewis B. Methods for dietary fiber, neutral detergent fiber, and nostarch polysaccharides in relation to animal nutrition. J. Dairy Sci. 1991;74:3583-3597.

21. Kafle G, Kim S. Anaerobic treatment of apple waste with swine manure for biogas production: batch and continuous operation. Appl. Energ. 2013;103:61-72.

22. Chen Y, Zhu R, Jiang Q, et al. Effects of green waste participation on the co-digestion of residual sludge and kitchen waste: A preliminary study. Sci. Total Environ. 2019;671:838-849.

23. Mao C, Wang X, Xi J, Feng Y, Ren G. Linkage of kinetic parameters with process parameters and operational conditions during anaerobic digestion. Energy 2017;135:352-360.

24. Nazlina H, Azusa I, Thomas K, et al. Oceans as bioenergy pools for methane production using activated methanogens in waste sewage sludge. Appl. Energ. 2017;202:399-407.

25. Chen Y, Zhao Z, Zou H, et al. Digestive performance of sludge with different crop straws in mesophilic anaerobic digestion. Bioresour. Technol. 2019;289:121595.

26. Xia T, Huang H, Wu G, Sun E, Jin X, Tang W. The characteristic changes of rice straw fibers in anaerobic digestion and its effect on rice straw-reinforced composites. Ind. Crop. Prod. 2018;121: 73-79.

27. Paul S, Dutta A. Challenges and opportunities of lignocellulosic biomass for anaerobic digestion. Resour. Conserv. Recy. 2018; 130:164-174.

28. Latha K, Velraj R, Shanmugam P, Sivanesan S. Mixing strategies of high solids anaerobic co-digestion using food waste with 
sewage sludge for enhanced biogas production. J. Clean. Prod. 2019;210:388-400.

29. Shao Y, Sun K, Li Q, et al. Dealkaline lignin-The waste from the pulp and paper industry as acid catalyst in biorefinery. Bioresour. Technol Reports. 2019;7:100218.

30. Amare D, Ogun M, Körner I. Anaerobic treatment of deinking sludge: Methane production and organic matter degradation. Waste Manage. 2019;85:417-424.

31. Brown D, Shi J, Li Y. Comparison of solid-state to liquid anaerobic digestion of lignocellulosic feedstocks for biogas production. Bioresour. Technol. 2012;124:379-386.

32. Chen S, He J, Wang H, Dong B, Li N, Dai X. Microbial responses and metabolic pathways reveal the recovery mechanism of an anaerobic digestion system subjected to progressive inhibition by ammonia. Chem. Eng. J. 2018;350:312-323.

33. Li Y, Chen Y, Wu J. Enhancement of methane production in anaerobic digestion process: A review. Appl. Energ. 2019;240:
120-137.

34. Li Y, Jin Y, Borrion A, Li H, Li J. Effects of organic composition on mesophilic anaerobic digestion of food waste. Bioresour. Technol. 2017;244:213-224.

35. Li Y, Luo W, Lu J, Zhang X, Li S. Effects of digestion time in anaerobic digestion on subsequent digestate composting. Bioresour. Technol. 2018;267:117-125.

36. Nizami A, Korres N, Murphy J. Review of the integrated process for the production of grass biomethane. Environ. Sci. Technol. 2009;43:8496-8508.

37. Shen F, Li H, Wu X, Wang Y, Zhang Q. Effect of organic loading rate on anaerobic co-digestion of rice straw and pig manure with or without biological pretreatment. Bioresour. Technol. 2018;250:155-162.

38. Dou W, Shen F, Yang G, et al. Can hydrothermal pretreatment improve anaerobic digestion for biogas from lignocellulosic biomass? Bioresour. Technol. 2018;249:117-124. 